International Journal of Engineering \& Technology, 7 (3.29)(2018) 57-60
International Journal of Engineering \& Technology
SPC
Website: $w$ ww.sciencepubco.com/index.php/IJET
Research paper

\title{
Varying operating frequency of concentric circular ring patch antenna using high impedance surface
}

\author{
Rangarao.Orugu $^{1 *}$, Srilatha.Gundapaneni ${ }^{2}$, N. Maryleena $^{3}$, A. K. Chaithanya Varma ${ }^{4}$ \\ ${ }^{I}$ Assistant. Professor, Dept. of ECE, Vishnu Institute of Technology, Bhimavaram, AP, India. \\ ${ }^{2}$ Assistant. Professor, Dept. of ECE, DNR college of Engg \& Tech,Bhimavaram, AP, India \\ ${ }^{3}$ Assistant. Professor, Dept. of ECE, Sir crr college of Engineering, Eluru, AP, India \\ ${ }^{4}$ Sr. Assistant. Professor, Dept. of ECE, Vishnu Institute of Technology, Bhimavaram, AP, India \\ *Corresponding author E-mail: ranga.mouni@gmail.com
}

\begin{abstract}
In this paper, we design a concentric circular patch antenna excited by microstrip feed and operates at $5.4269 \mathrm{GHz}$ and $6.9419 \mathrm{GHz}$. After designing the antenna, we would like to tune the frequency without changing antenna size. For that purpose, we use high impedance surface structure to tune the antenna at two different frequencies. A simple mushroom like structure is used as high impedance surface. We will analyze antenna parameters like return loss, gain, directivity, radiation patterns, efficiency, proposed antenna with and without high impedance surfaces and compare the results.
\end{abstract}

Keywords: Met Surfaces; Tuning; Concentric Circular Ring Patch; Strip Feed.

\section{Introduction}

In the past few decades the patch antennas proved to be very useful in many applications and development in modern communication systems to reach different specifications and needs different kinds of patch antennas were developed. Patch antennas are compact in size easy to fabricate and low production cost and can be integrated to the communication systems easily. In general they were developed with certain shapes like square, rectangular, circular, elliptical, etc[4]. but in the past few years so many different kinds of shapes were implemented and developed according certain applications, the patch antennas are also used in creating array antennas as a basic radiating element and the arrays will give even higher gain than the single radiating patch and also the fractal antennas were introduced further to reduce the array size and to obtain the same results as that of the array antennas. In the microstrip patch antennas concentric circular patch antennas are used for broadband [6], UWB [7], reconfigurable polarization [8] and many wireless communication applications.

High impedance surfaces also called as Metamaterials are initially implemented to suppress the surface wave propagation [1]. Because it does not allow certain waves to propagate, in other words it will mitigate the radiation passing through the antenna itself. It is also used to reflect the waves [5] with no phase shift so that the radiation energy will be added in constructive way so that the overall gain can be enhanced [2]. In general, these structures are constructed by placing metallic patches on metallic pin via and this periodic arrangement of such are placed on a metal base. Here the two adjacent patches and via together acts like a tuning circuit i.e the gap between the two metal plates will have fringing field and so that it acts like a capacitor $\mathrm{C}$ and the current pass through the pins will acts like a inductor L[3]. Together this LC combination will form a means to tune the design to different band of frequencies.

\section{Designing of proposed antenna and met sur- face}

a) Antenna Design

The proposed antenna design is shown in the following figure [1] the inner disc have a hallow space inside it of a radius of $\mathrm{R} 1=0.4 \mathrm{~cm}$ and disc arm R2 $=0.5 \mathrm{~cm}$. Another disc with a space of R3 $=0.4 \mathrm{~cm}$ and the disc arm R4=1cm. A dielectric substrate Rogers RT/duroid $5880(\mathrm{tm})$ having dielectric constant 2.2 and having lost tangents 0.0009 is considered and with dimensions of $9.1 \mathrm{~cm} \times 9.1 \mathrm{~cm} \times 62 \mathrm{mil}$ in $\mathrm{XYZ}$ directions respectively. The ground is $9.1 \mathrm{~cm} \times 9.1 \mathrm{~cm}$ in $\mathrm{XY}$ directions respectively. The proposed antenna is excited by microstrip feed. Here the strip line feed dimension $0.1 \mathrm{~cm} \times 2.15 \mathrm{~cm}$ in $\mathrm{XY}$ directions respectively. The feed connector dimensions $0.2 \mathrm{~cm} \times 0.2 \mathrm{~cm}$ in XY directions. The port is constructed in ZX plane with dimensions $0.2 \mathrm{~cm} \times 62 \mathrm{mil}$ in $\mathrm{X}$ and $\mathrm{Z}$ directions respectively. Here the port is normalized at 50ohms impedance 


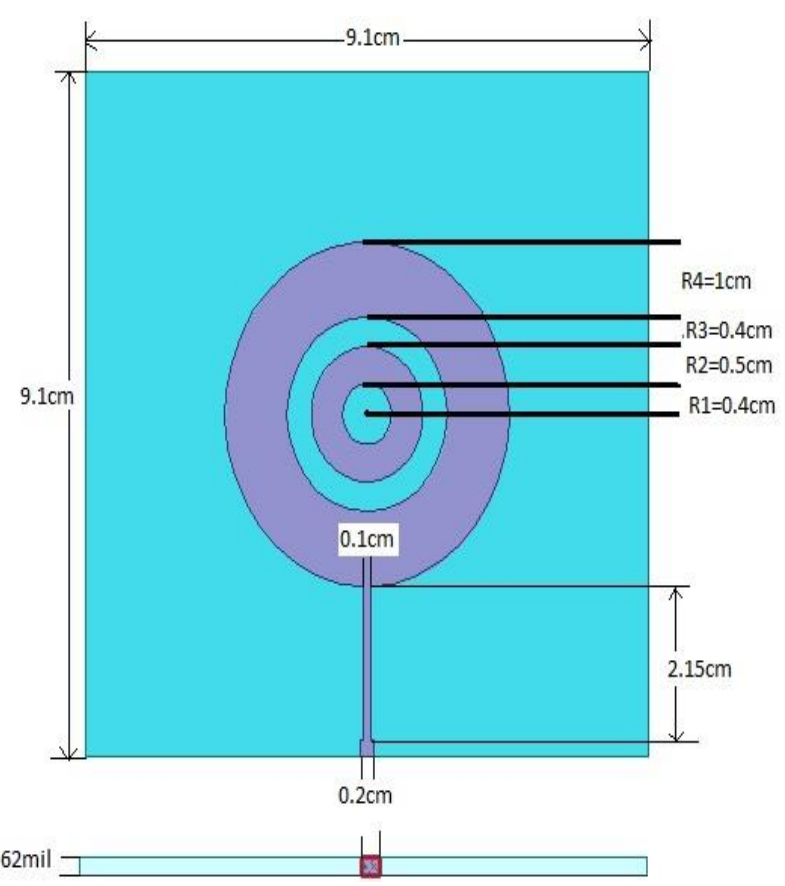

Fig. 1: Proposed Antenna Top View and Side View.

b) Met surface

The proposed high impedance surface is shown in the following figure [2]. Here the metallic patches supported by metal pins placed periodically on metallic base. Here the metallic base dimensions are same as ground. The metal plates are tuned into different sizes to have different gaps between adjacent plates but, the pins are kept constant at $\mathrm{h}=0.1 \mathrm{~cm}$ height so that inductance remains unchanged. Here the sizes of metallic plates varies between $g=0.7$ to 1.2

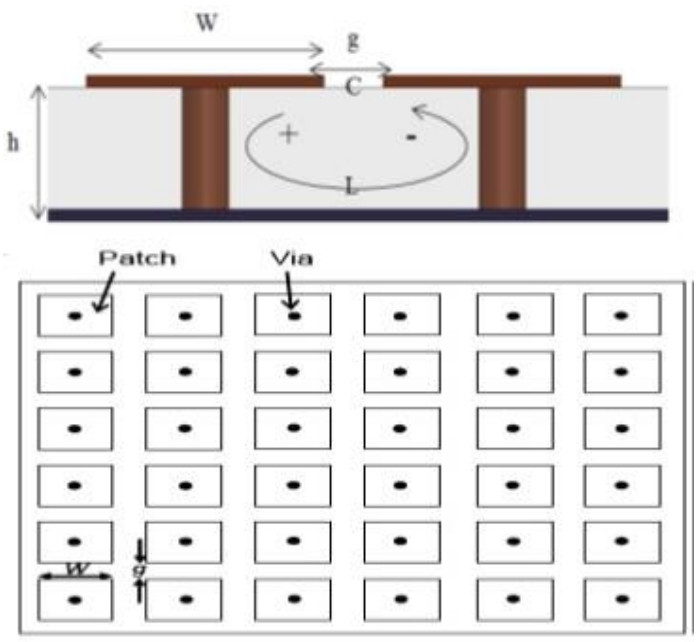

Fig. 2: HIS Side View and Top View.

\section{Simulated results and analysis}

Proposed antenna results

At first the proposed antennas is designed using the Ansys HFSS software and is illustrated as in the figure [3].
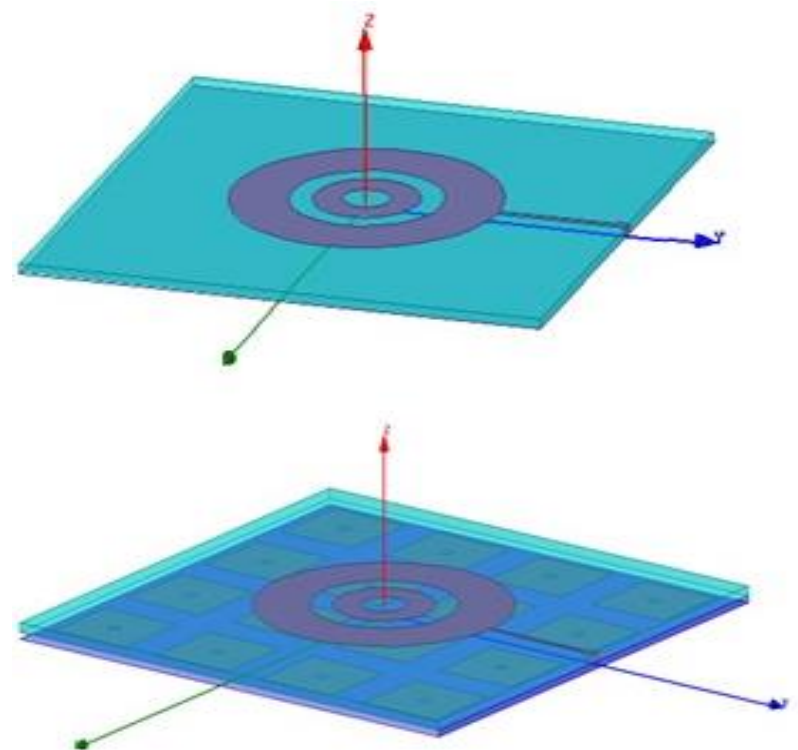

Fig. 3: Proposed Antenna Design Without and with Met Surface.

Return Loss curve

The return loss curve for the proposed antenna is as shown in the following figure [4]

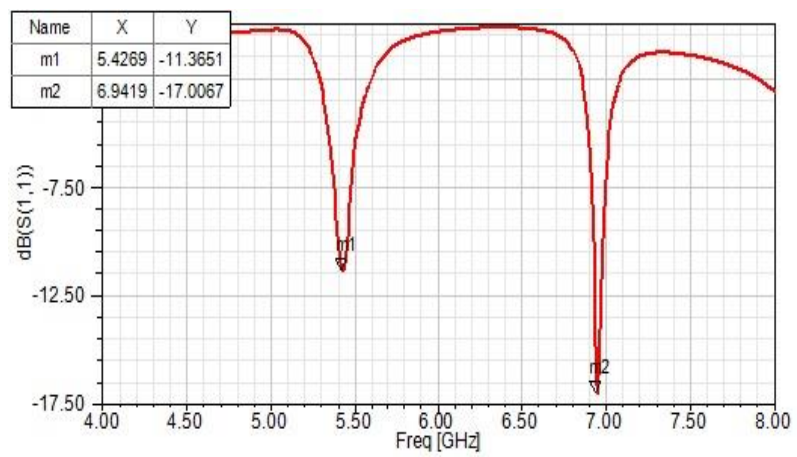

Fig. 4: Return Loss Curve for Proposed Antenna.

From the above figure [4] we can see that the proposed antenna works at dual frequencies $5.4269 \mathrm{GHz}$ and $6.9419 \mathrm{GHz}$ and the return loss occurred is $-11.3651 \mathrm{~dB}$ and $-17.0067 \mathrm{~dB}$ respectively.

Radiation Pattern

The radiation pattern curve for proposed antenna at $5.4269 \mathrm{GHz}$ at phi=0deg and phi=90deg is shown in the following figures [5]

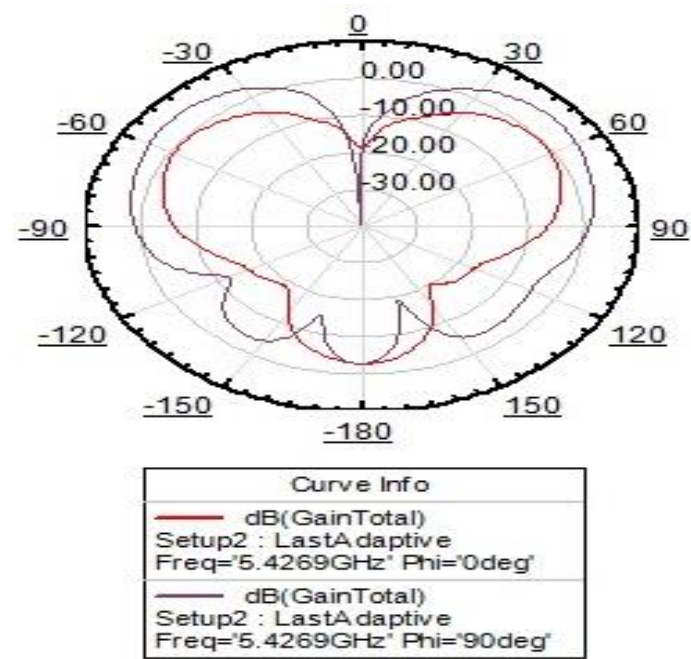

Fig. 5: Radiation Pattern at 5.4269 GHz Phi=0deg and Phi=90deg.

The radiation pattern curve for proposed antenna at $6.9419 \mathrm{GHz}$ at phi=0deg and phi=90deg is shown in the following figures 6 


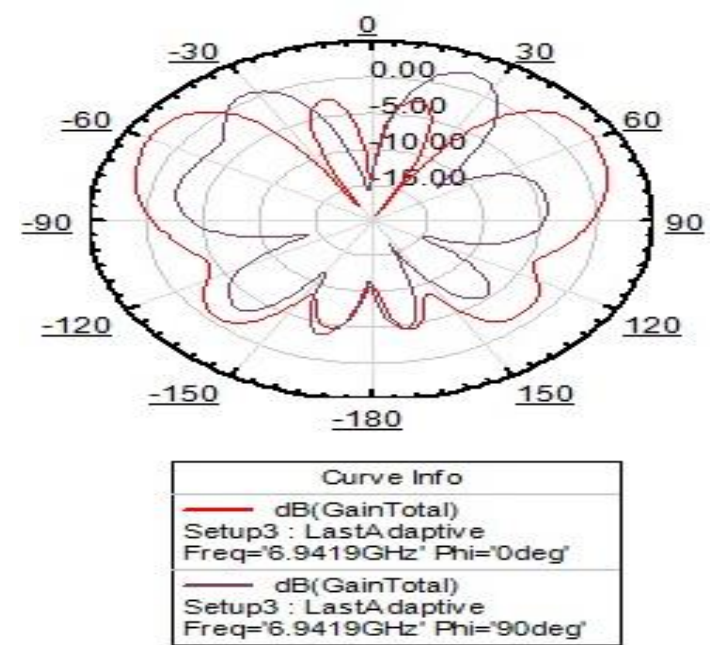

Fig. 6: Radiation Pattern at $6.9419 \mathrm{GHz}$ Phi=0deg and Phi=90deg.

Now the proposed antenna is analyzed by placing a high impedance surface as its ground and the gap between plates $\mathrm{g}$ is varied from $\mathrm{g}=0.7$ to $1.2 \mathrm{~cm}$ and the comparative return loss curve is as shown in the following figure [7]

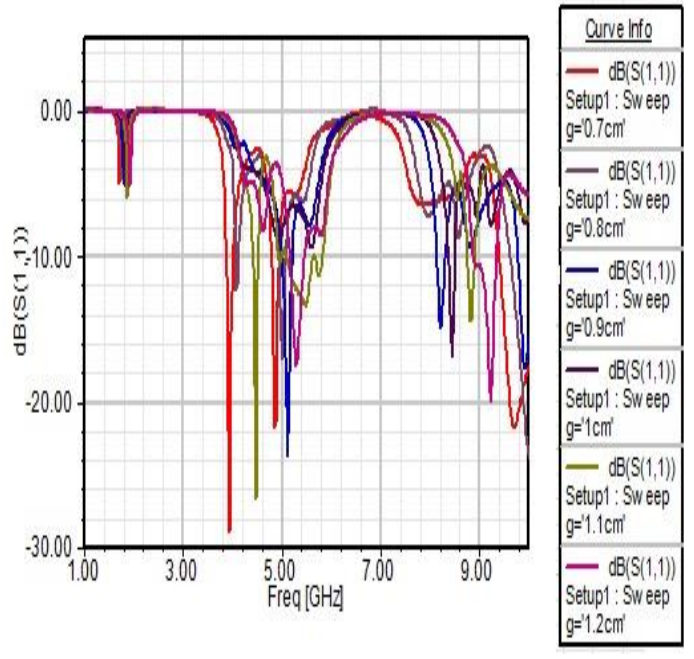

Fig. 7: Comparison of Return Loss Curves when $\mathrm{G}=0.7$ to $1.2 \mathrm{~cm}$.

The comparison of radiation patterns for all $g$ values at their respective operating frequencies are illustrated in the following figure [8].
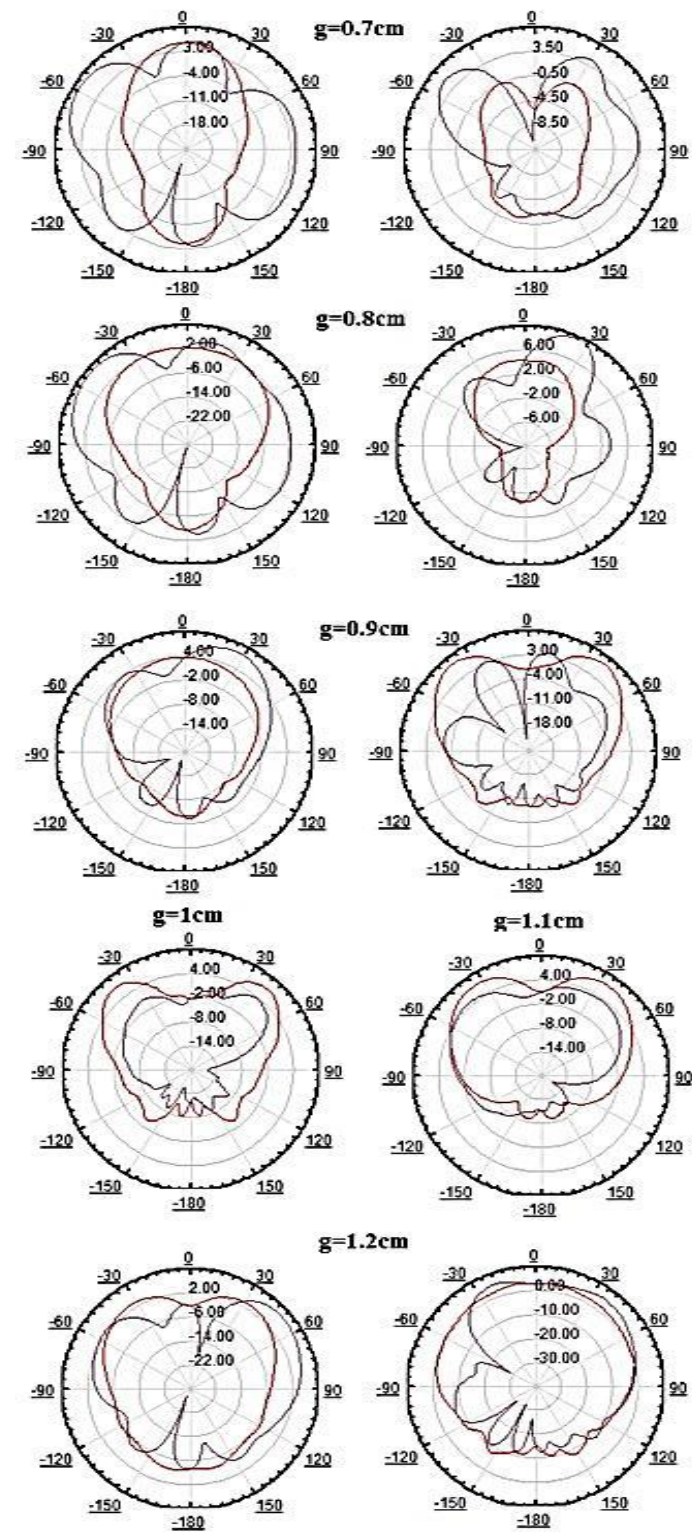

Fig. 8: Radiation Pattern Comparison for $G=0.7$ to $G=1.2 \mathrm{~cm}$ for the Proposed Antenna at Their Respective Change of Operating Frequencies.

In addition, for clear understanding for all changes of $g$ and the conventional antenna are compared with the operating frequencies and their return loss values are illustrated in the following Table [1].

Table 1: Frequency and Return Loss Comparison for Conventional Antenna and Antenna with HIS as $\mathrm{G}=0.7$ to $1 \mathrm{~cm}$

\begin{tabular}{llll}
\hline $\mathrm{S}$. No & Type & Freq $(\mathrm{GHz})$ & Return $\operatorname{loss}(\mathrm{dB})$ \\
\hline \multirow{2}{*}{1} & \multirow{2}{*}{ Proposed antenna } & 5.4269 & -11.3651 \\
& & 6.9419 & -17.0067 \\
2 & $\mathrm{~g}=0.7 \mathrm{~cm}$ & 3.9399 & -28.7807 \\
& & 4.8597 & -21.6445 \\
3 & $\mathrm{~g}=0.8 \mathrm{~cm}$ & 4.0842 & -12.2429 \\
& & 5.004 & -16.9207 \\
4 & $\mathrm{~g}=0.9 \mathrm{~cm}$ & 5.1122 & -23.5803 \\
5 & $\mathrm{~g}=1 \mathrm{~cm}$ & 8.2144 & -14.8236 \\
6 & $\mathrm{~g}=1.1 \mathrm{~cm}$ & 8.4489 & -16.7583 \\
7 & $\mathrm{~g}=1.2 \mathrm{~cm}$ & 4.481 & -26.4892 \\
& & 5.2926 & -17.4167 \\
\hline
\end{tabular}

\section{Conclusion}

Concentric circular antenna with microstrip feed is designed and its operating frequency is tuned to lower and frequencies and as well as higher frequencies all in between $1 \mathrm{GHz}$ to $10 \mathrm{Ghz}$ by using the high impedance surface and all of them have given satisfied results 
and the variation of $g$ value sometimes it caused very good results some time the results are just average.

\section{References}

[1] Sievenpiper, D., "High-impedance electromagnetic surfaces," Ph.D. Thesis, University of California, Los Angeles, 1999.

[2] J. Doondi kumar, "Analysis of Monopole Antenna by Placing High Impedance Absorber Surface at one Side" /Volume-2Number-1PP317-321.

[3] Filippo costa, an active High impedance surface for low profile Tunable and steerable Antennas, IEEE ANTENNAS AND WIRELESS PROPAGATION LETTER, VOL 7, 2008.

[4] C. Balanis, Antenna theory, Analysis, and Design 2nd ed., John Wiley and sons, New York (1997).

[5] Yang, F. and Y. Rahmat-Samii, "Reflection phase characterization of the EBG ground plane for low profile wire antenna applications," IEEE Trans. Antennas Propag., Vol. 51, No. 10, 2691-2703, 2003.

[6] Garima, D. Batnagar "Design of broadband cmicrostrip circular patch antenna with diamond shape slot" Indian journal of Radio and space physics, volume 40, oct-2011, pp 275-281.

[7] S. Azzaz-Rahmani, N. Boukli-Hacene, "Ultra-Wide-Band Microstrip Concentric Annular Ring Antenna for Wireless Communications", IJCSI, vol 9 issue 1, pp 132-134.

[8] B. Babakhani, "Wideband frequency tunable concentric circular microstrip patch antenna with simultaneous polarization reconfiguration", IEEE Antennas and propagation, vol 57, issue two, pp-203216

[9] P. GAO, L. Xiong, J. B. Dai, S. He, and Y. Zheng, "Compact printed wide-slot UWB antenna with 3.5/5.5-GHz dual band-notched characteristics," IEEE Antennas Wireless Propag. Lett. vol. 12, pp. 983986, 2013. 